Review Article

\title{
Complex Membrane Channel Blockade: A Unifying Hypothesis for the Prodromal and Acute Neuropsychiatric Sequelae Resulting from Exposure to the Antimalarial Drug Mefloquine
}

\begin{abstract}
Jane C. Quinn
Plant and Animal Toxicology Group, School of Animal and Veterinary Sciences, Graham Centre for Agricultural Innovation, Charles Sturt University, Boorooma Street, Wagga Wagga, NSW 2650, Australia
\end{abstract}

Correspondence should be addressed to Jane C. Quinn; jquinn@csu.edu.au

Received 22 July 2015; Accepted 28 September 2015

Academic Editor: Ashley M. Croft

Copyright (C) 2015 Jane C. Quinn. This is an open access article distributed under the Creative Commons Attribution License, which permits unrestricted use, distribution, and reproduction in any medium, provided the original work is properly cited.

\begin{abstract}
The alkaloid toxin quinine and its derivative compounds have been used for many centuries as effective medications for the prevention and treatment of malaria. More recently, synthetic derivatives, such as the quinoline derivative mefloquine (bis(trifluoromethyl)-(2-piperidyl)-4-quinolinemethanol), have been widely used to combat disease caused by chloroquineresistant strains of the malaria parasite, Plasmodium falciparum. However, the parent compound quinine, as well as its more recent counterparts, suffers from an incidence of adverse neuropsychiatric side effects ranging from mild mood disturbances and anxiety to hallucinations, seizures, and psychosis. This review considers how the pharmacology, cellular neurobiology, and membrane channel kinetics of mefloquine could lead to the significant and sometimes life-threatening neurotoxicity associated with mefloquine exposure. A key role for mefloquine blockade of ATP-sensitive potassium channels and connexins in the substantia nigra is considered as a unifying hypothesis for the pathogenesis of severe neuropsychiatric events after mefloquine exposure in humans.
\end{abstract}

\section{Background}

Quinine is an alkaloid toxin found in the bark of the South American cinchona (quina-quina) tree [1]. Quinine and its derivative compounds have been used since the 1800 s as a homeopathic remedy for analgesia and also as an effective treatment for malaria [2]. Despite its proven efficacy as a schizonticidal agent against the malaria parasite Plasmodium falciparum during its intraerythrocytic phase, quinine suffers from a number of contraindications which have made it problematic as an effective therapeutic including a low therapeutic index and high incidence of adverse side effects [3]. Despite this, and a lack of efficacious alternatives, quinine remained the most widely used antimalarial until the 1920 s when a new breed of compounds was discovered. Drugs such as chloroquine then became the treatment of choice for malarial prophylaxis and were used widely in all areas with endemic malaria for many decades [4].
By the 1950s, increasing levels of chloroquine resistance necessitated a push for the discovery of novel compounds for malarial chemoprophylaxis [5]. The synthetic quinoline derivative mefloquine (bis(trifluoromethyl)-(2-piperidyl)-4quinolinemethanol) [6], an effective antimalarial but potent neurotoxin, was identified as part of this discovery process. First synthesised in the late 1960s, mefloquine's potent antimalarial properties were identified as part of a two-phase US military drug discovery programme that was mounted to identify novel antimalarial compounds for use primarily in their theatres of operation in Southeast Asia [4, 5, 710]. Studies showed that chloroquine and mefloquine acted via the same erythrocyte accumulation mechanism, but with mefloquine showing greater affinity, likely the mechanism for its increased efficacy both as a treatment and a prophylactic compared to chloroquine [11]. Despite historical knowledge of quinine and quinoline-induced related adverse drug reactions $[7,12]$, including hearing loss, visual disturbances, and 
severe hypoglycaemia [13-15], mefloquine was expeditiously developed with the assistance of the US Government and the pharmaceutical company Hoffmann La Roche [16, 17] and released following limited clinical testing $[18,19]$.

Over the next twenty years mefloquine was widely advocated as the drug of choice for travellers to areas known to be endemic for chloroquine-resistant malaria [20] such as subSaharan Africa [21, 22]. During this time, it was reported to be "well tolerated, safe, and effective" [23] despite coincident reports of significant neuropsychiatric side effects in isolated cases [24]. During the 1990s and 2000s, an increasing body of clinical case material reported significant neuropsychiatric side effects presenting in patients taking mefloquine for malarial prophylaxis [25-33]. Clinical presentation included a range of neurological symptoms in previously healthy individuals which included tremor, balance disturbances, fatigue, nausea, dizziness, anxiety or panic attacks, sleep disturbances including insomnia and vivid nightmares, visual disturbances, and hearing loss [31, 34], as well as severe neuropsychiatric sequelae including major personality change, psychosis, seizures, suicidal ideation, and suicide completion $[26,27,31-33,35,36]$.

This "toxidrome," a collection of significant neurological symptoms affecting balance, vision, hearing, memory, personality, and emotional status, has now been described as a limbic encephalopathy with central vestibulopathy [37], an overarching diagnosis covering all the possible manifestations of this complex neurotoxicity. This review will consider how mefloquine might induce this wide range of clinical effects in the central nervous system and explores current knowledge surrounding its binding partners at the cell surface. It will also present evidence suggesting destabilisation or destruction of the brain's central pacemaker, the substantia nigra, as a unifying hypothesis underlying many of the neuropsychiatric features of mefloquine toxicity.

\section{Pharmacokinetics and \\ Bioavailability: Implications for Clinical Presentation of Neurotoxicity Resulting from Mefloquine Exposure}

The incidence of adverse reactions to mefloquine treatment and/or prophylaxis has long been a point of controversy. Early studies suggested that patients did not experience the very severe neuropsychiatric side effects that had been reported with chloroquine [38-42] but as increasing numbers of adverse events began to be reported in the literature, this opinion changed. Recently, controlled clinical trials have suggested that the incidence of neuropsychiatric side effects in travellers using mefloquine for malarial prophylaxis as well as those for treatment of malaria was more than a hundredfold greater than had been suggested in early studies investigating drug safety [32, 43-46]. However, despite significant reporting of the clinical manifestations of mefloquine toxicity [31], factors underlying the variability in presentation and severity of clinical signs observed in a subset of patients presenting with significant adverse reactions have yet to be fully elucidated.
Some of the pharmacological properties of mefloquine, which contribute to its efficacy as an antimalarial, may also contribute to its neurotoxicity. Mefloquine has a long plasma half-life (13-28 days), which contributes to its efficacy as a prophylactic treatment achievable by easy weekly dosing [47, 48]. Mefloquine is also highly lipophilic and exhibits stereoselective passage across the blood brain barrier (BBB) [48-51]. In the brain, highest concentrations have been reported in the hippocampus and subcortical areas in rodent studies $[52,53]$ with samples from human postmortem tissues shown to be up to 10 -fold higher than plasma levels [50, 54].

One mechanism likely to cause increased retention of mefloquine in the CNS is via inhibition of the membrane efflux pump P-glycoprotein. P-gp (also known as ATPBinding Cassette protein 1, ABC1), encoded by the MultiDrug Resistance gene 1 (MDR1), is a transmembrane protein found lining the brain capillary endothelium that plays a specific role in central neuroprotection by restricting access of lipophilic molecules across the BBB [55]. The normal function of P-gp is to protect the brain from neurotoxic attack by limiting CNS access to complex molecules; mefloquine has been shown to be a potent inhibitor of P-glycoprotein [56], blocking its action at the $\mathrm{BBB}$ and causing retention of mefloquine in nervous tissues.

Effectiveness of the CYP450 enzyme superfamily in oxidative enzymatic degradation of common pharmaceuticals, including mefloquine, is likely to also play a significant role in the presentation and severity of neuropsychiatric side effects as genetic polymorphisms in the enzymes CYP2D6, CYP2C19, CYP3A4, and CYP1A2 [57] have all been implicated in adverse reactions to common antidepressants including incidences involving significant violence and suicide [58]. In these cases, ultrarapid metabolism was linked to suicide and extreme violence $[58,59]$ resulting from rapid conversion to toxic metabolites or bioactive drug production, whilst activity caused by single or multiple allelic mutation can cause failure of systemic depletion of the parent compound, with increased risk of adverse reactions to common neuropsychiatric drugs [57]. Recently, the relationship between treatments responses and genetic polymorphism at the CYP2A6 and CYP2B6 loci were investigated in patients receiving dual artesunate-mefloquine treatment for $P$. falciparum malaria [60] where mutations in CYP2A6 were related to poorer treatment outcomes due to reduced metabolic conversion of artesunate to dihydroartemisinin. Serum level of mefloquine was not measured but it might be assumed that these would also be high as low dose chloroquine has been shown recently to induce severe neuropsychiatric symptoms in an individual with mutation of the CYP2A6 and altered CYP450 activity [61], symptoms that were further exacerbated by treatment with other common psychiatric drugs. These findings suggest that allelic variation in CYP450 significantly increases the risk of severe neuropsychiatric sequelae on exposure to quinoline derivatives and further pharmacogenetic studies are warranted to investigate this possibility.

Mutations in genes associated with cellular metabolism of toxic compounds are not the only polymorphisms implicated in increased risk of adverse neuropsychiatric events associated with quinoline therapy. Mutations at the MNDR1 locus 
have also been shown to be associated with a heightened sensitivity to mefloquine in vitro [62] as well as being correlated with an increased incidence of neuropsychiatric side effects in humans particularly in women [63]. The malarial homologue of P-gp is also implicated in conferring chloroquine resistance to some strains of Plasmodium falciparum $[63,64]$ suggesting a common role and important role for these transmembrane proteins in restricting passage of mefloquine into cells under normal condition.

The highly lipophilic nature of mefloquine is also likely to be a contributory factor to the variable presentation of adverse neuropsychiatric events in humans. It has been shown that travellers with a low body weight index, taking mefloquine for malarial prophylaxis, showed an increased likelihood of adverse reactions than those taking chloroquine or the combination therapy chloroquine and proguanil [32]. This is likely due to reduced binding of the active compound to body fat stores and therefore a preferential compartmentalisation in other lipophilic tissues, such as the brain. Certainly volume of distribution is known to play a key role in drug toxicity and it has been well documented for mefloquine's parent molecule quinine that compartmentalisation, elimination, and excretion are all affected by age and health status of the patient. In particular, rates of elimination have been found to be slower in the elderly and those suffering from acute malaria than young or well individuals $[47,65]$ and similar effects have been identified in patients with active malarial infection treated with mefloquine [66].

Together, these findings suggest that variability in plasma half-life, activity of efflux pumps of the CNS/vascular interface, and compartmentalisation, as well as underlying genetics regulating neuroactive drug sensitivity and metabolism, may all contribute to toxic loading of mefloquine in the CNS and therefore the highly variable presentation of adverse events in a subpopulation of mefloquine users. Thus, multiple factors affecting drug retention and concentration in the CNS make accurate prediction of adverse events in patients exposed to mefloquine highly problematic.

\section{Mefloquine Receptor Channels and Binding Partners: Relating Clinical Signs of Mefloquine Neurotoxicity to Intracellular Interactions in the Central Nervous System}

It has been well described that toxic loading of mefloquine in the CNS can be subject to significant interpersonal variation; however, this does not fully explain the highly varied expression of adverse side effects reported by individuals exposed to therapeutic levels of mefloquine. At toxic doses, mefloquine has been widely reported to cause neuronal dysfunction, axonal degeneration, and neuronal cell death in a variety of cell types of the central nervous system [67-70], yet in some patients it appears to be able to elicit these significant and detrimental effects at much lower doses. How mefloquine induces multiple effects across a range of different neuronal subtypes is not yet clear but understanding its membrane binding partners in the CNS, and effects on cell membrane excitability, could give some clues as to its varying modes of toxicity in the human brain.

\section{Mefloquine Exerts Receptor Blockade of ATP-Sensitive Potassium Channels $\left(\mathrm{K}_{\mathrm{ATP}}\right)$}

One family of neuronal cell membrane channels likely to play a key role in mefloquine neurotoxicity are the octomeric ATP-sensitive potassium $\left(\mathrm{K}_{\mathrm{ATP}}\right)$ channels. $\mathrm{K}_{\mathrm{ATP}}$ channels are found in a wide range of tissues, including cardiomyocytes, smooth muscle, hormone secreting cells of the pancreas, and neurons of the CNS $[71,72] . \mathrm{K}_{\text {ATP }}$ channels contain two components, a pore-forming Kir subunit and a sulfonylurea receptor (SUR) subunit, members of the ATPbinding cassette superfamily $[73,74]$. A number of variants of these receptor subcomponents have now been identified, with different subunit pairings found in different cell types in the body. The Kir subunit forms the channel pore and contains the ATP-inhibition site, whilst the SUR subunit is sensitive to sulphonylureas and channel agonists [7577]. $K_{\text {ATP }}$ channels have been shown to play a fundamental role in glucose homeostasis via their activity in insulinsecreting islet cells of the pancreas [78-81] and are also widely distributed throughout the brain, in particular, being found within the cell membranes of postsynaptic $\gamma$-aminobutyric acid (GABA) inhibitory neurons of the cerebral cortex, substantia nigra pars reticulata $(\mathrm{SNr})$, pars compacta (SNc), and cerebellum [73, 77, 82-84].

In neurons, $\mathrm{K}_{\mathrm{ATP}}$ channels modulate the availability of ATP for cellular metabolism by responding to depletion of ATP resources within the cell. Their activation results in opening of the $\mathrm{K}_{\mathrm{ATP}}$ channel causing membrane hyperpolarisation. Therefore, in neurons under normal metabolic conditions, $\mathrm{K}_{\text {ATP }}$ channels are closed, only opening when the intracellular ATP/ADP ratio decreases sufficiently to required metabolic homeostasis to be restored (Figure 1). What is important in the context of neurotoxicity is that this modulation in ATP-dependent membrane excitability confers dual properties to the cell: (1) influencing maintenance of normal spontaneous firing patterns as well as (2) conferring neuroprotective properties to the cell in instances of metabolic stress, such as in hypoxia or ischaemia [82, 85]. $K_{\text {ATP }}$ channel blockade alters neuronal excitability and negates the neuroprotective effect, potentially leaving cells susceptible to ischaemic or excitotoxic cell death under conditions of metabolic stress or disease (Figure 1).

Initial clues as to a role for $\mathrm{K}_{\mathrm{ATP}}$ channels in mefloquine toxicity came from studies investigating metabolic abnormalities in patients treated with quinine and its derivatives. Mefloquine, chloroquine, quinoline, and quinine have all been shown to block the activity of $\mathrm{K}_{\mathrm{ATP}}$ channels in islet cells of the pancreas, increasing insulin secretion $[86,87]$. This finding, associated with reports of severe hypoglycaemia in patients undergoing treatment with both quinine and mefloquine for malarial prophylaxis or acute disease $[15,88$, 89], suggests a similar mode of action for the two compounds in the pancreas in humans [86]. Quinine and quinoline derivatives, therefore, are likely to impede $\mathrm{K}_{\mathrm{ATP}}$ channel 


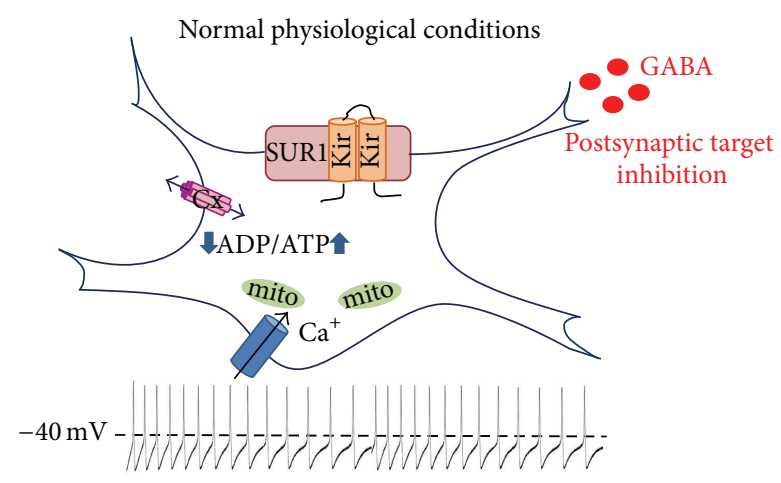

(a)

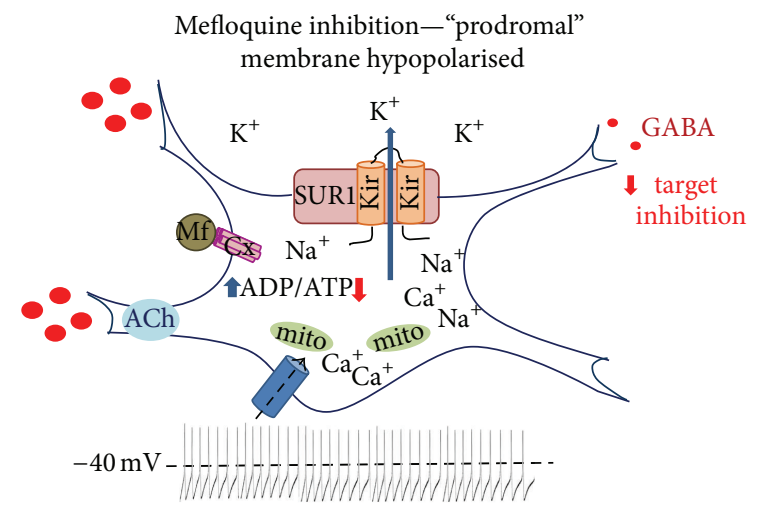

(c)

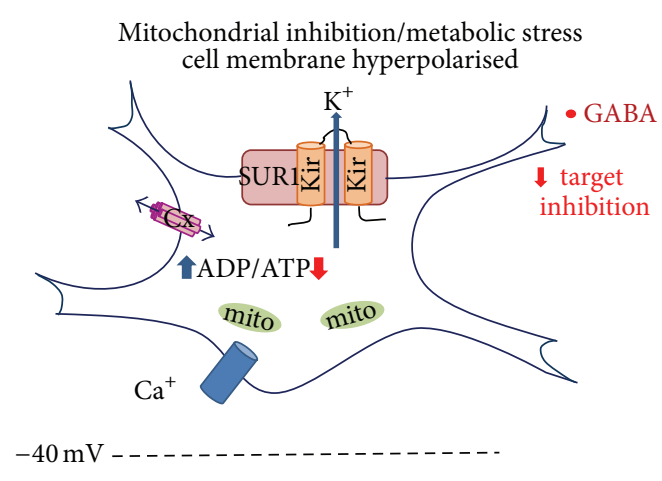

(b)

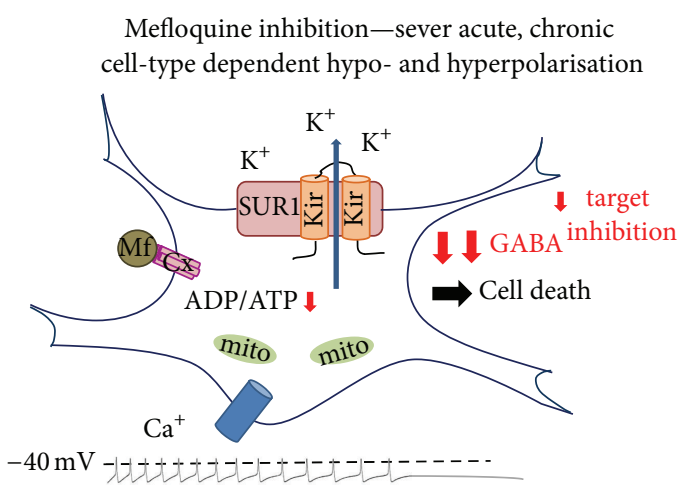

(d)

FIGURE 1: $\mathrm{K}_{\mathrm{ATP}}$ channels found within the cell membrane of both pre- and postsynaptic neurons of the substantia nigra (SNr) and ventral tegumental area (VTA), as well as other brain regions. In the SNr and VTA, the majority of $\mathrm{K}_{\text {ATP }}$ neurons are dopaminergic and exert GABAergic inhibition on their postsynaptic targets. (a) Within these cells, under normal physiological conditions, $\mathrm{K}_{\mathrm{ATP}}$ channels are closed and ligandgated calcium channels are free to open allowing hypopolarisation of the cell membrane and tonic excitation. Connexin channels (Cx) are also open allowing for exchange of ions, metabolites, and second messengers to enable appropriate electrical coupling. (b) Under conditions of metabolic stress or hypoxia, ATP depletion causes $\mathrm{K}_{\mathrm{ATP}}$ channels to open and $\mathrm{Ca}^{+}$channels to close, hyperpolarising the cell membrane and conferring neuroprotective proprieties by inhibiting neuronal excitation. Inhibition of target cells is diminished due to reduction in GABA release, stimulating hypopolarisation in postsynaptic targets. Connexin channels are hypothesised to remain open under these conditions. (c) In the presence of low concentrations of mefloquine, K-ATP channels are inhibited and remain open in the absence of metabolic stress, causing potassium efflux from the cell and increased transport of sodium into the cell through this open cation pore. This sodium influx causes an initial hypopolarisation, increasing tonic firing and initially enhancing presynaptic GABA release. Increased activity of $\mathrm{Na}^{+} \mathrm{K}^{+}-\mathrm{ATPase}$ transmembrane channels increases metabolic stress, ensuring that $\mathrm{K}_{\mathrm{ATP}}$ channels remain open. GABA release is, initially, further enhanced by inhibition of cholinesterase (ChE) which results in accumulation of endogenous acetylcholine (ACh) in the presynaptic terminal. Continued exposure is likely to result in intracellular ATP depletion, and finally GABA depression, resulting in a loss of postsynaptic inhibition. In addition, mefloquine (Mf) blocks connexin channel transport, further dysregulating intra- and intercellular excitability, giving rise to additional neuropsychiatric symptoms such as focal cortical or limbic seizures. (d) Exposure to high levels of mefloquine, or continued long-term exposure, would result in complete inhibition of $\mathrm{K}_{\mathrm{ATP}}$ channel closure, continued connexin channel blockade, and permanent dysregulation of postsynaptic inhibition by presynaptic GABAergic inhibition as well as exerting significant neuronal metabolic stress, finally resulting in metabolic cell death in the basal neuron and potentiating excitotoxic cell death target neurons in other brain regions. Adapted from Liss and Roeper [140].

function in other tissues such as the brain and there is growing evidence to support this hypothesis.

\section{5. $\mathrm{K}_{\mathrm{ATP}}$ Channel Blockade and Limbic Seizures}

$\mathrm{K}_{\mathrm{ATP}}$ are widely distributed throughout the brain and have been shown to be present in GABA-responsive neurons of the cerebral cortex, substantia nigra pars reticulata $(\mathrm{SNr})$, pars compacta $(\mathrm{SNc})$, and cerebellum $[73,82]$. Of particular relevance to this review is the finding that GABAergic neurons of the $\mathrm{SNr}$ have been shown to express $\mathrm{K}_{\mathrm{ATP}}$ channels, cells which are known to play a key role in maintenance of normal spontaneous firing activity in the brain [84, 90]. This spontaneous excitation pattern has been described as the "fast spiking pacemaker" of the central nervous system, instructing the tonic output activity of the basal ganglia and other subcortical regions, and is fundamentally required for normal neurological function [91].

Under normal metabolic conditions, $\mathrm{K}_{\mathrm{ATP}}$ channels in the $\mathrm{SNr}$ are closed and cells exhibit a high level of spontaneous 
activity, suppressing seizure activity by release of GABA onto postsynaptic terminals (Figure 1(a)). Conversely, in states of metabolic tension, such as hypoxia, these channels are activated causing a protective hyperpolarisation due to calcium efflux, and thus reducing membrane excitability (Figure 1(b)) [82]. $\mathrm{K}_{\mathrm{ATP}}$ channels in the $\mathrm{SNr}$ have been shown to play a significant role in both neuronal protection and seizure suppression $[82,92]$ with the majority of neurons in the $\mathrm{SNr}$ being GABAergic and exhibiting high levels of spontaneous firing [90]. Mefloquine inhibition of $\mathrm{SNr} \mathrm{K}_{\mathrm{ATP}}$ channels would open the membrane pore, initially maintaining high levels of spontaneous activity and GABA release regardless of metabolic status (Figure 1(c)). Continued inhibition would result in depletion of cellular metabolic stores, reducing GABA release $[93,94]$, and finally cell death of $\mathrm{SNr}$ neurons (Figure 1(d)). This blockade would also confer an inability to regulate excitability in target neurons of the mesostriatal dopaminergic pathway, similar to the hyperexcitability observed in hypoglycaemia [95], increasing dopamine release and potentially resulting in excitotoxic cell death in target neuron populations (Figure 1). $\mathrm{K}_{\mathrm{ATP}}$ membrane mefloquine channel inhibition would also reduce the neuroprotective ability of midbrain neurons to respond to metabolic ATP depletion making them more sensitive to metabolic stress in states or injury or disease. Mefloquine could therefore induce both neuronal dysfunction and cell death in this critical regulatory region of the brain.

Another interesting and relevant finding is that extracellular dopamine levels in the striatum increases as the base firing rate of $\mathrm{SNr}$ neurons increases [96]. This biochemical change could potentially deregulate the delicate balance between serotonergic and dopaminergic control of the mesolimbic system (Figure 2), such as what is seen in the alterations of mood and behaviour associated with states of addiction to psychostimulants [97] and neuronal synchronisation characteristic of limbic seizures. Limbic seizures are classified as psychogenic seizure events without major epileptiform changes, which result in paroxysmal episodic alteration in cognitive function, behaviour, and emotional control [98-101]. These two conditions have apparent similarities to mefloquine toxicity. A number of studies support this hypothesis. Firstly, the SNr has been identified to be the site of action of the anticonvulsant topiramate in the intrahippocampal pilocarpine model of limbic seizures, exerting its action by either direct connection to the hippocampus or indirect subcortical connections via the striatum (Figure 2) [102-106]. Secondly, sustained opening of $K_{\text {ATP }}$ channels was induced by mild hypoxia in mice without a functional Kir6.2 subunit, causing neuronal depolarisation and enhanced membrane sensitivity, sufficient to cause excitotoxic cell death $[82,85]$. Seizure activity induced by mefloquine antagonism resulting from loss or dysregulation of SNr tonic firing could therefore give rise to a number of the side effects observed in clinical cases of mefloquine toxicity, including significant neuropsychiatric disturbances.

Effects of mefloquine exposure to cells of the SNr has been examined in some detail in vitro [94]. Mefloquine has been shown to cause hyperexcitation in primary dopaminergic neurons of the SNr, increasing pacemaker firing activity in a concentration dependent manner [94]. Significantly, this effect was observed at concentrations far lower than those found in the plasma of patients treated with mefloquine for malarial prophylaxis $(0.3-10 \mathrm{mM}$ compared to $3.8-23 \mathrm{mM}$ in humans). This study also showed that this increased firing pattern enhanced $\mathrm{GABA}_{\mathrm{A}}$-receptor mediated synaptic transmission by increasing intracellular calcium and inhibition of cholinesterase [94]. In a whole animal system, this could result in sustained binding of endogenous acetylcholine to its receptors, potentially causing some of the adverse neurobehavioural and cognitive effects reported in patients undergoing mefloquine treatment. Whilst this hypothesis does not account for all of the prodromal and acute neuropsychiatric symptoms associated with exposure to mefloquine, and further work is needed to evaluate the role of cholinergic stimulation in mefloquine toxicosis, it is compatible with a past description of mefloquine toxicity as a central anticholinergic syndrome [107] as well as known correlations between anticholinergic medications and impaired cognitive and motor function [108, 109].

Together these studies suggest that mefloquine blockade of $\mathrm{K}_{\mathrm{ATP}}$ channels in the $\mathrm{SNr}$ could manifest as many of the abnormal behaviours, including heightened states of anxiety, aggression, antisocial or criminal behaviour, or seizures, widely associated with mefloquine toxicity, a hypothesis that could be investigated further in human patients experiencing adverse reactions to mefloquine prophylaxis or treatment $[36,37,110,111]$.

\section{6. $K_{\mathrm{ATP}}$ Channels in Movement, Auditory, and Visual Pathways, Implications for a Role in Mefloquine Toxicosis}

Further evidence exists to support a hypothesis of a role for $\mathrm{K}_{\mathrm{ATP}}$ channels, and their blockade, in clinical presentation of movement, auditory, and visual disturbances associated with mefloquine toxicity. Neurons of the SNr interact with subcortical areas directly via the striato-nigral pathway and indirectly through the striato-pallido-subthalamic-nigral pathway, the former exerting a strong GABA-mediated inhibitory role on more posterior brain regions, including the cerebellum via connections in the pedunculopontine tegmental nucleus (Figure 2) $[90,112] . \mathrm{K}_{\text {ATP }}$ channels are both pre- and postsynaptic in this pathway. GABAergic neurons of the striatum express $\mathrm{K}_{\mathrm{ATP}}$ channels on their terminal axons, as well as postsynaptic channels being present on SNr neurons themselves [113]. In the nigropedunculopontine pathway, SNr neurons extend direct connections to pontine cerebellar structures, the superior colliculus, and the pedunculopontine tegmental nucleus [112], where they play a role in modulation of saccadic and pursuit eye movements in response to sensory and attention signals from the cortex, as well as balance and coordination. A dysregulation of inhibitory input to visual or auditory centres could therefore account for auditory and visual hallucinations frequently reported in cases of mefloquine psychosis [37, 114-117].

A link between neuronal activity in the $\mathrm{SNr}$ and $\mathrm{K}_{\mathrm{ATP}}$ mefloquine blockade may also underlie some of 


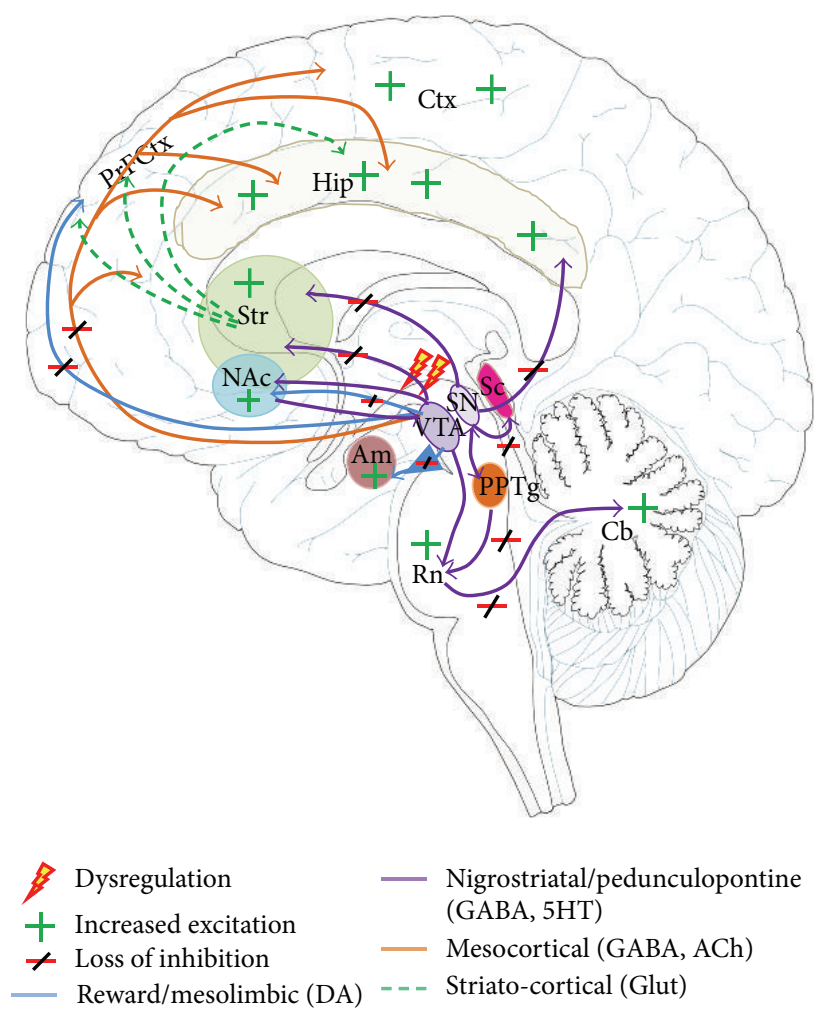

Figure 2: Pathways in the brain implicated in the clinical presentation of mefloquine toxicity. Loss of ascending inhibition within the nigrostriatal-pedunculopontine, mesolimbic and mesocortical pathways, resulting in hyperactivation of neurons in the amygdala, striatum, nucleus accumbens, and cortical and hippocampal areas, as well as within descending pathways to the Raphe nuclei, and cerebellum could give rise to the complex neuropsychiatric sequelae observed in patients exposed to prophylactic and treatment doses of mefloquine. Secondary disinhibition of striato-cortical pathways is implicated in seizure and motor and cognitive changes observed in affected individuals.

the variation in presentation of adverse effects noted in travellers and patients using mefloquine for malarial prophylaxis or treatment. The $\mathrm{SNr}$ is a region of the brain slow to reach functional maturity [118] and shows sex specific differences in its activity [119]. It has been reported that children tolerate mefloquine treatment better than adults and male better than female patients [120]. These functional differences in the $\mathrm{SNr}$ between juveniles, adults, and the elderly, as well as between men and women, could account for some of the significant variation observed in adverse effects of mefloquine treatment and prophylaxis.

Genetic variance or mutation in the $\mathrm{K}_{\mathrm{ATP}}$ channel subunit genes Kir6.2 and SUR1 could underlie some of the interpersonal variation observed in patients suffering from adverse effects of mefloquine exposure. Genetic variation in Kir6.2 and SUR1 subunits have been shown to cause both Type 1 and Type 2 diabetes, as well as epilepsy in humans [121-125]. As such, genetic variation in these genes might therefore predispose some individuals to more severe adverse events when taking quinoline derivatives, such as mefloquine, for malarial prophylaxis or treatment. Genetic screening for sequence variations in the Kir6.2 and SUR1 subunits in patients presenting with severe neuropsychiatric symptoms after mefloquine exposure could begin to define these connections more definitively and provide a better understanding as to the origin of the clinical variation presenting in cases of mefloquine toxicity.

\section{7. $\mathrm{K}_{\mathrm{ATP}}$ Channels, Connexins, and Intercellular Connections in Mefloquine Toxicity}

The connection between mefloquine disruptions of interneuronal communication via blockade of connexins channels, a family of gap junction family proteins, is now well established [126]. Like $\mathrm{K}_{\mathrm{ATP}}$ channels, connexins (Cx) play an important role in neuronal metabolism and homeostasis by controlling movement of ions, metabolites, and other molecules between adjacent cells of the CNS. Gap junctions establish electrical coupling by allowing intercellular exchange of ions and metabolic support by transport of ADP, glucose, glutamate, and glutathione, as well as movement of second messengers such as cyclic AMP. A wide variety of pharmacological agents have been shown to influence their activity [127] and dysfunction of connexin channel activity, or their blockade, has been implicated in a number of neuropsychiatric disorders common with mefloquine toxicity including suicide completion [128], vestibular dysfunction [129], and epilepsy [130]. 


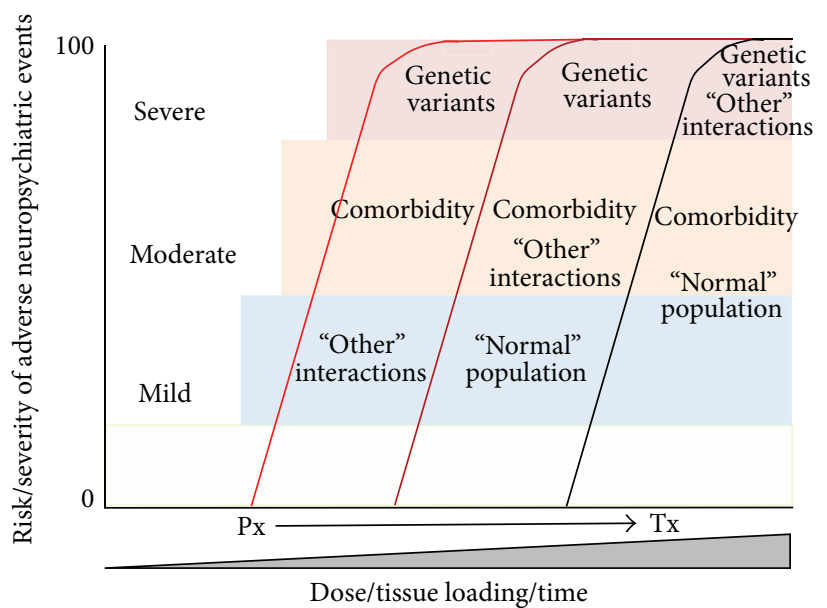

FIGURE 3: The hypothetical relationship between risk and severity of adverse neuropsychiatric reactions in patients exposed to prophylactic $(\mathrm{Px})$ or treatment $(\mathrm{Tx})$ doses of mefloquine and their relation to the presence of genetic variation, such as $\mathrm{K}_{\mathrm{ATP}}$ channel subunit variants, CYP450, MDR1, and connexin allelic mutations, comorbidity with other neuropsychiatric disorders and "other" currently identified comorbid factors such as alcohol intake, low body mass index, age, immune suppression, and concurrent malarial disease. Within the "normal" population at low doses mild to moderate neuropsychiatric symptoms are common, with this proportion increasing with increasing doses at treatment. At low $(\mathrm{Px})$ doses, individuals with predisposing conditions, such as pharmacogenetic predisposition, or comorbidity, will manifest more severe adverse reactions more quickly than the "normal" population. Individuals with additional compounding comorbid factors will present the most severe symptoms most quickly. Treatment doses will elicit the most severe symptoms, most quickly, in those with single or multiple predisposing conditions as well as in an increased proportion of the "normal" population exposed to this drug.

There is a known functional connection between connexins and $\mathrm{K}_{\mathrm{ATP}}$ channels in states of neuropsychiatric abnormality. It has been shown that $\mathrm{K}_{\text {ATP }}$ channels regulate the expression of $\mathrm{Cx} 43$ and $\mathrm{Cx} 45$ in the epileptic hippocampus [131]. Cx36 is widely expressed in cortical, subcortical, and limbic regions of the brain and has been implicated as a player in mefloquine toxicosis $[132,133]$. Interestingly, Cx36 is also expressed by dopaminergic neurons of the SNr and GABAergic neurons of the ventral tegumental area $[134,135]$, again linking activity of connexins to those membrane effects of $\mathrm{K}_{\mathrm{ATP}}$ channels in these regions. Both mefloquine and quinine have been shown to selectively block the activity of $\mathrm{Cx} 36$ and Cx50 channels in vitro, mefloquine with significantly higher potency than its parent molecule $[126,136,137]$ and mefloquine inhibition of $\mathrm{Cx} 36$ in the inferior olive in humans has been shown to diminish motor learning skills [138].

A connection between mefloquine, connexins, and altered neurosensory function has also been identified. Mefloquine inhibits Cx26, dominant mutations of which have been shown to cause neurosensory deafness as well as attenuating increased membrane currents in primary cells expressing a dominant negative human Cx26 channel [139]. Cx26 is also expressed in neurons of the $\mathrm{SNr}$ [134]. The possibility of dual dysfunction of both $\mathrm{K}_{\mathrm{ATP}}$ and connexin membrane channels (Figures $1(\mathrm{c})$ and $1(\mathrm{~d})$ ), giving rise to both intra- and intercellular changes in neuronal metabolism and activity, could therefore underlie some of the very severe neuropsychiatric events observed in cases of mefloquine toxicity.

Together, these studies suggest a synergistic role for connexins regulating intercellular excitability, and $\mathrm{K}_{\mathrm{ATP}}$ channels regulating intracellular metabolism, in the pathogenesis of mefloquine toxicity via multiplex membrane channel blockade. Variation in the sensitivity of either or both membrane channels, due to age, genetic variation, interaction with other gap junction blockers, or channel antagonists, could explain the extreme variation in neuropsychiatric symptoms presenting in patients exposed to supposedly "safe" levels of mefloquine.

\section{Conclusions}

Significant evidence now exists for a primary role for membrane channel blockade in the presentation and severity of adverse neuropsychiatric reactions in patients exposed to mefloquine at normal prophylactic or treatment levels. How these complex cellular interactions manifest as neuroelectrophysiological and neurochemical changes, synaptic dysfunction, or neuronal cell death is still not clear but it seems likely that the delicate balance between excitation and inhibition caused by mefloquine exposure, both intra- and intercellularly, is likely to play a central role with connexins and $\mathrm{K}_{\text {ATP }}$ channels both implicated in this process. A diagrammatic representation of the complex interrelationship between risk and severity of adverse events, pharmacogenetics, comorbidity with other neuropsychiatric disorders, and dose/length of exposure is illustrated in Figure 3. Reduced activity or blockade of both of these membrane channels in the brain's central pacemaker and the substantia nigra pars reticulata, as well as increased sensitivity to mefloquine due to underlying allelic variation, could provide an overarching hypothesis bringing together many of the diverse neuropsychiatric events reported in cases of mefloquine toxicoses.

Further studies, including functional and structural imaging of deep brain regions in patients suffering from mefloquine toxicity and examination of electrophysiological changes in cells of the substantia with mutation or variation 
in both $\mathrm{K}_{\mathrm{ATP}}$ and connexin channels on exposure to mefloquine, could begin to elucidate the delicate interplay between excitation and inhibition in cases of mefloquine toxicoses. A hypothesis of dysfunction of the central pacemaker, giving rise to mesolimbic dysregulation, could also provide novel treatment options for patients suffering from adverse reactions to mefloquine exposure in the future.

\section{Conflict of Interests}

The author declares that there is no conflict of interests regarding the publication of this paper.

\section{References}

[1] D. M. Aviado, R. Rosen, H. Dacanay, and S. H. Plotkin, "Antimalarial and antiarrhythmic activity of plant extracts. I. Cinchona and quinine in Plasmodium berghei in immature rats," Medicina Experimentalis, vol. 19, no. 2, pp. 79-94, 1969.

[2] J. Achan, A. O. Talisuna, A. Erhart et al., "Quinine, an old anti-malarial drug in a modern world: role in the treatment of malaria," Malaria Journal, vol. 10, article 144, 2011.

[3] G. Pasvol, "The treatment of complicated and severe malaria," British Medical Bulletin, vol. 75-76, no. 1, pp. 29-47, 2005.

[4] G. R. Coatney, "Pitfalls in a discovery: the chronicle of chloroquine," The American Journal of Tropical Medicine and Hygiene, vol. 12, pp. 121-128, 1963.

[5] R. E. Blount, W. D. Tigertt, and R. E. Blount Jr., "Chloroquineresistant falciparum malaria," The Journal of the American Medical Association, vol. 202, no. 10, p. 989, 1967.

[6] M. W. Davidson, B. G. Griggs Jr., D. W. Boykin, and W. D. Wilson, "Mefloquine, a clinically useful quinolinemethanol antimalarial which does not significantly bind to DNA," Nature, vol. 254, no. 5501, pp. 632-634, 1975.

[7] R. W. Berliner and T. C. Butler, Summary of Data on the Drugs Tested in Man. A Survey of Antimalarial Drugs, 1941-1945, vol. 1, Edwards Brothers, Ann Arbor, Mich, USA, 1946.

[8] W. D. Tigertt, “The army malaria research program," Annals of Internal Medicine, vol. 70, no. 1, pp. 150-153, 1969.

[9] L. H. Schmidt, R. Crosby, J. Rasco, and D. Vaughan, "Antimalarial activities of various 4-quinolinemethanols with special attention to WR-142,490 (Mefloquine)," Antimicrobial Agents and Chemotherapy, vol. 13, no. 6, pp. 1011-1030, 1978.

[10] W. D. Tigertt, "Present and potential malaria problem," Military Medicine, vol. 131, no. 9, supplement, pp. 853-856, 1966.

[11] C. D. Fitch, R. L. Chan, and R. Chevli, "Chloroquine resistance in malaria: accessibility of drug receptors to mefloquine," Antimicrobial Agents and Chemotherapy, vol. 15, no. 2, pp. 258$262,1979$.

[12] A. C. Loken and W. Haymaker, "Pamaquine poisoning in man, with a clinicopathologic study of one case," The American Journal of Tropical Medicine and Hygiene, vol. 29, no. 3, pp. 341$352,1949$.

[13] K. K. Karlsson, U. Hellgren, G. Alván, and L. Rombo, "Audiometry as a possible indicator of quinine plasma concentration during treatment of malaria," Transactions of the Royal Society of Tropical Medicine and Hygiene, vol. 84, no. 6, pp. 765-767, 1990.

[14] R. E. Phillips, S. Looareesuwan, and N. J. White, "Hypoglycaemia and antimalarial drugs: quinidine and release of insulin," British Medical Journal, vol. 292, no. 6531, pp. 1319-1321, 1986.
[15] G. N. Ogetii, S. Akech, J. Jemutai et al., "Hypoglycaemia in severe malaria, clinical associations and relationship to quinine dosage," BMC Infectious Diseases, vol. 10, article 334, 2010.

[16] T. H. Maugh, "Malaria-resurgence in research brightens prospects," Science, vol. 196, no. 4288, pp. 413-416, 1977.

[17] T. H. Maugh, "Malaria drugs: new ones are available, but little used," Science, vol. 196, no. 4288, p. 415, 1977.

[18] G. M. Trenholme, R. L. Williams, R. E. Desjardins et al., "Mefloquine (WR 142,490) in the treatment of human malaria," Science, vol. 190, no. 4216, pp. 792-794, 1975.

[19] K. H. Rieckmann, G. M. Trenholme, R. L. Williams, P. E. Carson, H. Frischer, and R. E. Desjardins, "Prophylactic activity of mefloquine hydrochloride (WR 142490) in drug resistant malaria," Bulletin of the World Health Organization, vol. 51, no. 4, pp. 375-377, 1974.

[20] A. P. Hall, “The treatment of malaria," British Medical Journal, vol. 1, no. 6005, pp. 323-328, 1976.

[21] D. N. Bhattacharya and A. P. Hall, "Chloroquine-resistant falciparum malaria from East Africa," Journal of Tropical Medicine and Hygiene, vol. 89, no. 6, pp. 291-294, 1986.

[22] D. Chabasse, L. De Gentile, C. Ligny, J. Le Bras, X. Rialland, and J. P. Bouchara, "Chloroquine-resistant Plasmodium falciparum in Mali revealed by congenital malaria," Transactions of the Royal Society of Tropical Medicine and Hygiene, vol. 82, no. 4, p. 547, 1988.

[23] World Health Organization, "Development of mefloquine as an antimalarial drug. UNDP/World Bank/WHO update," Bulletin of the World Health Organization, vol. 61, no. 2, pp. 169-178, 1983.

[24] T. Harinasuta, D. Bunnag, and W. H. Wernsdorfer, "A phase II clinical trial of mefloquine in patients with chloroquineresistant Falciparum malaria in Thailand," Bulletin of the World Health Organization, vol. 61, no. 2, pp. 299-305, 1983.

[25] G. C. Cook, "Malaria prophylaxis. Mefloquine toxicity should limit its use to treatment alone," British Medical Journal, vol. 311, no. 6998, pp. 190-192, 1995.

[26] E. Caillon, L. Schmitt, and P. Moron, "Acute depressive symptoms after mefloquine treatment," American Journal of Psychiatry, vol. 149, no. 5, article 712, 1992.

[27] C. Hennequin, P. Bourée, N. Bazin, F. Bisaro, and A. Feline, "Severe psychiatric side effects observed during prophylaxis and treatment with mefloquine," Archives of Internal Medicine, vol. 154, no. 20, pp. 2360-2362, 1994.

[28] J. M. K. Ekue, A. M. Ulrich, J. R. Atenyi, and U. K. Sheth, "A double-blind comparative clinical trial of mefloquine and chloroquine in symptomatic falciparum malaria," Bulletin of the World Health Organization, vol. 61, no. 4, pp. 713-718, 1983.

[29] L. C. Patchen, C. C. Campbell, and S. B. Williams, "Neurologic reactions after a therapeutic dose of mefloquine," The New England Journal of Medicine, vol. 321, no. 20, pp. 1415-1416, 1989.

[30] T. M. Tran, J. Browning, and M. L. Dell, "Psychosis with paranoid delusions after a therapeutic dose of mefloquine: a case report," Malaria Journal, vol. 5, article 74, 2006.

[31] A. Ringqvist, P. Bech, B. Glenthøj, and E. Petersen, "Acute and long-term psychiatric side effects of mefloquine: a follow-up on Danish adverse event reports," Travel Medicine and Infectious Disease, vol. 13, no. 1, pp. 80-88, 2015.

[32] N. Corominas, J. Gascón, T. Mejías et al., "Adverse drug reactions associated to the antimalarial chemoprophylaxis," Medicina Clinica, vol. 108, no. 20, pp. 772-775, 1997. 
[33] E. Pous, J. Gascón, J. Obach, and M. Corachan, "Mefloquineinduced grand mal seizure during malaria chemoprophylaxis in a non-epileptic subject," Transactions of the Royal Society of Tropical Medicine and Hygiene, vol. 89, no. 4, article 434, 1995.

[34] F. O. Ter Kuile, F. Nosten, C. Luxemburger et al., "Mefloquine treatment of acute falciparum malaria: a prospective study of non-serious adverse effects in 3673 patients," Bulletin of the World Health Organization, vol. 73, no. 5, pp. 631-642, 1995.

[35] A. L. Peterson, R. A. Seegmiller, and L. S. Schindler, "Severe neuropsychiatric reaction in a deployed military member after prophylactic mefloquine," Case Reports in Psychiatry, vol. 2011, Article ID 350417, 4 pages, 2011.

[36] E. C. Ritchie, J. Block, and R. Lee Nevin, "Psychiatric side effects of mefloquine: applications to forensic psychiatry," Journal of the American Academy of Psychiatry and the Law, vol. 41, no. 2, pp. 224-235, 2013.

[37] R. L. Nevin, "Limbic encephalopathy and central vestibulopathy caused by mefloquine: a case report," Travel Medicine and Infectious Disease, vol. 10, no. 3, pp. 144-151, 2012.

[38] K. K. Mustakallio, T. Putkonen, and T. A. Pihkanen, "Chloroquine psychosis?” The Lancet, vol. 2, no. 7270, pp. 1387-1388, 1962.

[39] A. C. Dornhorst and B. F. Robinson, "Chloroquine psychosis?" The Lancet, vol. 281, no. 7272, p. 108, 1963.

[40] B. S. Bomb, H. K. Bedi, and L. K. Bhatnagar, "Chloroquine psychosis," Transactions of the Royal Society of Tropical Medicine and Hygiene, vol. 69, no. 5-6, p. 523, 1975.

[41] O. L. Sapp, “Toxic psychosis due to quinacrine and chloroquine," JAMA: The journal of the American Medical Association, vol. 187, no. 5, pp. 373-375, 1964.

[42] A. M. Rønn, J. Rønne-Rasmussen, P. C. Gøtzsche, and I. C. Bygbjerg, "Neuropsychiatric manifestations after mefloquine therapy for Plasmodium falciparum malaria: comparing a retrospective and a prospective study," Tropical Medicine \& International Health, vol. 3, no. 2, pp. 83-88, 1998.

[43] D. Overbosch, H. Schilthuis, U. Bienzle et al., "Atovaquoneproguanil versus mefloquine for malaria prophylaxis in nonimmune travelers: results from a randomized, double-blind study," Clinical Infectious Diseases, vol. 33, no. 7, pp. 1015-1021, 2001.

[44] C. R. Meier, K. Wilcock, and S. S. Jick, "The risk of severe depression, psychosis or panic attacks with prophylactic antimalarials," Drug Safety, vol. 27, no. 3, pp. 203-213, 2004.

[45] T. Weinke, M. Trautmann, T. Held et al., "Neuropsychiatric sideeffects after the use of mefloquine," The American Journal of Tropical Medicine and Hygiene, vol. 45, no. 1, pp. 86-91, 1991.

[46] D. O. Freedman, "Clinical practice: malaria prevention in shortterm travelers," The New England Journal of Medicine, vol. 359, no. 6, pp. 603-612, 2008.

[47] N. J. White, "Clinical pharmacokinetics of antimalarial drugs," Clinical Pharmacokinetics, vol. 10, no. 3, pp. 187-215, 1985.

[48] J. Karbwang and N. J. White, "Clinical pharmacokinetics of mefloquine," Clinical Pharmacokinetics, vol. 19, no. 4, pp. 264279, 1990.

[49] R. Chevli and C. D. Fitch, "The antimalarial drug mefloquine binds to membrane phospholipids," Antimicrobial Agents and Chemotherapy, vol. 21, no. 4, pp. 581-586, 1982.

[50] Y. T. Pham, F. Nosten, R. Farinotti, N. J. White, and F. Gimenez, "Cerebral uptake of mefloquine enantiomers in fatal cerebral malaria," International Journal of Clinical Pharmacology and Therapeutics, vol. 37, no. 1, pp. 58-61, 1999.
[51] Y.-T. Pham, A. Régina, R. Farinotti et al., "Interactions of racemic mefloquine and its enantiomers with P-glycoprotein in an immortalised rat brain capillary endothelial cell line, GPNT," Biochimica et Biophysica Acta-General Subjects, vol. 1524, no. 2-3, pp. 212-219, 2000.

[52] S. Baudry, Y. T. Pham, B. Baune et al., "Stereoselective passage of mefloquine through the blood-brain barrier in the rat," Journal of Pharmacy and Pharmacology, vol. 49, no. 11, pp. 1086-1090, 1997.

[53] M. Brickelmaier, A. Lugovskoy, R. Kartikeyan et al., "Identification and characterization of mefloquine efficacy against JC virus in vitro," Antimicrobial Agents and Chemotherapy, vol. 53, no. 5, pp. 1840-1849, 2009.

[54] R. Jones, G. Kunsman, B. Levine, M. Smith, and C. Stahl, "Mefloquine distribution in postmortem cases," Forensic Science International, vol. 68, no. 1, pp. 29-32, 1994.

[55] D. S. Miller, "Regulation of P-glycoprotein and other ABC drug transporters at the blood-brain barrier," Trends in Pharmacological Sciences, vol. 31, no. 6, pp. 246-254, 2010.

[56] S. B. de Lagerie, E. Comets, C. Gautrand et al., "Cerebral uptake of mefloquine enantiomers with and without the P-gp inhibitor elacridar (GF1210918) in mice," British Journal of Pharmacology, vol. 141, no. 7, pp. 1214-1222, 2004.

[57] M. Ingelman-Sundberg and S. C. Sim, "Pharmacogenetic biomarkers as tools for improved drug therapy; emphasis on the cytochrome P450 system," Biochemical and Biophysical Research Communications, vol. 396, no. 1, pp. 90-94, 2010.

[58] Y. Lucire and C. Crotty, "Antidepressant-induced akathisiarelated homicides associated with diminishing mutations in metabolizing genes of the CYP450 family," Pharmacogenomics and Personalized Medicine, vol. 4, no. 1, pp. 65-81, 2011.

[59] A. L. Zackrisson, B. Lindblom, and J. Ahlner, "High frequency of occurrence of CYP2D6 gene duplication/multiduplication indicating ultrarapid metabolism among suicide Cases," Clinical Pharmacology \& Therapeutics, vol. 88, no. 3, pp. 354-359, 2010.

[60] P. Phompradit, P. Muhamad, A. Cheoymang, and K. NaBangchang, "Preliminary investigation of the contribution of CYP2A6, CYP2B6, and UGT1A9 polymorphisms on artesunate-mefloquine treatment response in Burmese patients with Plasmodium falciparum malaria," The American Journal of Tropical Medicine and Hygiene, vol. 91, no. 2, pp. 361-366, 2014.

[61] N. M. Maxwell, R. L. Nevin, S. Stahl et al., "Prolonged neuropsychiatric effects following management of chloroquine intoxication with psychotropic polypharmacy," Clinical Case Reports, vol. 3, no. 6, pp. 379-387, 2015.

[62] D. A. Barnes, S. J. Foote, D. Galatis, D. J. Kemp, and A. F. Cowman, "Selection for high-level chloroquine resistance results in deamplification of the pfmdrl gene and increased sensitivity to mefloquine in Plasmodium falciparum," The EMBO Journal, vol. 11, no. 8, pp. 3067-3075, 1992.

[63] A. L. H. J. Aarnoudse, R. H. N. van Schaik, J. Dieleman et al., "MDR1 gene polymorphisms are associated with neuropsychiatric adverse effects of mefloquine," Clinical Pharmacology and Therapeutics, vol. 80, no. 4, pp. 367-374, 2006.

[64] A. F. Cowman and S. Karcz, "Drug resistance and the Pglycoprotein homologues of Plasmodium falciparum," Seminars in Cell Biology, vol. 4, no. 1, pp. 29-35, 1993.

[65] N. J. White, P. Chanthavanich, S. Krishna, C. Bunch, and K. Silamut, "Quinine disposition kinetics," British Journal of Clinical Pharmacology, vol. 16, no. 4, pp. 399-403, 1983.

[66] S. Looareesuwan, N. J. White, D. A. Warrell et al., "Studies of mefloquine bioavailability and kinetics using a stable isotope 
technique: a comparison of Thai patients with falciparum malaria and healthy caucasian volunteers," British Journal of Clinical Pharmacology, vol. 24, no. 1, pp. 37-42, 1987.

[67] D. Ding, W. Qi, D. Yu et al., "Addition of exogenous NAD ${ }^{+}$ prevents mefloquine-induced neuroaxonal and hair cell degeneration through reduction of caspase-3-mediated apoptosis in cochlear organotypic cultures," PLoS ONE, vol. 8, no. 11, Article ID e79817, 2013.

[68] D. Z. Yu, D. Ding, H. Jiang, D. Stolzberg, and R. Salvi, "Mefloquine damage vestibular hair cells in organotypic cultures," Neurotoxicity Research, vol. 20, no. 1, pp. 51-58, 2011.

[69] G. S. Dow, T. H. Hudson, M. Vahey, and M. L. Koenig, "The acute neurotoxicity of mefloquine may be mediated through a disruption of calcium homeostasis and ER function in vitro," Malaria Journal, vol. 2, article 14, 2003.

[70] J. E. Hood, J. W. Jenkins, D. Milatovic, L. Rongzhu, and M. Aschner, "Mefloquine induces oxidative stress and neurodegeneration in primary rat cortical neurons," NeuroToxicology, vol. 31, no. 5, pp. 518-523, 2010.

[71] S. Seino, "ATP-sensitive potassium channels: a model of heteromultimeric potassium channel/receptor assemblies," Annual Review of Physiology, vol. 61, pp. 337-362, 1999.

[72] T. Miki, N. Inagaki, K. Nagashima, T. Gonoi, and S. Seino, "Structure and function of ATP-sensitive potassium channels," in Potassium Ion Channels: Molecular Structure, Function, and Diseases, vol. 46, chapter 20, pp. 373-385, Elsevier, 1999.

[73] N. Inagaki, T. Gonoi, J. P. Clement IV et al., "A family of sulfonylurea receptors determines the pharmacological properties of ATP-sensitive $\mathrm{K}^{+}$channels," Neuron, vol. 16, no. 5, pp. 10111017, 1996.

[74] N. Inagaki, Y. Tsuura, N. Namba et al., "A novel Atp-sensitive K+ channel widely expressed in rat-tissues, including pancreaticislets," Diabetes, vol. 44, p. A22, 1995.

[75] A. P. Babenko, G. Gonzalez, and J. Bryan, "The N-terminus of $\mathrm{K}_{\mathrm{IR}} 6.2$ limits spontaneous bursting and modulates the ATP-inhibition of $\mathrm{K}_{\mathrm{ATP}}$ channels," Biochemical and Biophysical Research Communications, vol. 255, no. 2, pp. 231-238, 1999.

[76] A. P. Babenko and J. Bryan, "SUR-dependent modulation of KATP channels by an N-terminal KIR6.2 peptide: defining intersubunit gating interactions," The Journal of Biological Chemistry, vol. 277, no. 46, pp. 43997-44004, 2002.

[77] S. Wang, L.-F. Hu, Y. Yang, J.-H. Ding, and G. Hu, "Studies of ATP-sensitive potassium channels on 6-hydroxydopamine and haloperidol rat models of Parkinson's disease: implications for treating Parkinson's disease?" Neuropharmacology, vol. 48, no. 7, pp. 984-992, 2005.

[78] F. M. Ashcroft and F. M. Gribble, "Correlating structure and function in ATP-sensitive $\mathrm{K}^{+}$channels," Trends in Neurosciences, vol. 21, no. 7, pp. 288-294, 1998.

[79] Q. Zhang, R. Ramracheya, C. Lahmann et al., "Role of K-ATP channels in glucose-regulated glucagon secretion and impaired counterregulation in type 2 diabetes," Cell Metabolism, vol. 18, no. 6, pp. 871-882, 2013.

[80] F. M. Ashcroft and F. M. Gribble, "ATP-sensitive $\mathrm{K}^{+}$channels and insulin secretion: their role in health and disease," Diabetologia, vol. 42, no. 8, pp. 903-919, 1999.

[81] M. Suzuki, K. Fujikura, N. Inagaki, S. Seino, and K. Takata, "Localization of the ATP-sensitive $\mathrm{K}^{+}$channel subunit Kir6.2 in Mouse pancreas," Diabetes, vol. 46, no. 9, pp. 1440-1444, 1997.

[82] K. Yamada and N. Inagaki, "Neuroprotection by K-ATP channels," Journal of Molecular and Cellular Cardiology, vol. 38, no. 6, pp. 945-949, 2005.
[83] K. P. S. J. Murphy and S. A. Greenfield, "ATP-sensitive potassium channels counteract anoxia in neurones of the substantia nigra," Experimental Brain Research, vol. 84, no. 2, pp. 355-358, 1991.

[84] A. Lutas, L. Birnbaumer, and G. Yellen, "Metabolism regulates the spontaneous firing of substantia nigra pars reticulata neurons via KATPand nonselective cation channels," The Journal of Neuroscience, vol. 34, no. 49, pp. 16336-16347, 2014.

[85] K. Yamada, Juan Juan Ji, H. Yuan et al., "Protective role of ATPsensitive potassium channels in hypoxia-induced generalized seizure," Science, vol. 292, no. 5521, pp. 1543-1546, 2001.

[86] F. M. Gribble, T. M. E. Davis, C. E. Higham, A. Clark, and F. M. Ashcroft, "The antimalarial agent mefloquine inhibits ATPsensitive K-channels," British Journal of Pharmacology, vol. 131, no. 4, pp. 756-760, 2000.

[87] F. M. Gribble, C. Higham, A. Clarke, F. M. Ashcroft, and T. M. E. Davis, "The antimalarial drugs mefloquine and halofantrine inhibit ATP-sensitive potassium channels," Diabetologia, vol. 40, p. 401, 1997.

[88] D. Kerr and A. Bdiri, "Quinine-associated hypoglycaemia causing diabetes," Diabetic Medicine, vol. 25, no. 2, pp. 241-242, 2008.

[89] R. Assan, C. Perronne, L. Chotard, E. Larger, and J. L. Vilde, "Mefloquine-associated hypoglycaemia in a cachectic AIDS patient," Diabete et Metabolisme, vol. 21, no. 1, pp. 54-57, 1995.

[90] F. Windels and E. A. Kiyatkin, "GABA, not glutamate, controls the activity of substantia nigra reticulata neurons in awake, unrestrained rats," Journal of Neuroscience, vol. 24, no. 30, pp. 6751-6754, 2004.

[91] D. J. Surmeier, J. N. Mercer, and C. S. Chan, "Autonomous pacemakers in the basal ganglia: who needs excitatory synapses anyway?" Current Opinion in Neurobiology, vol. 15, no. 3, pp. 312-318, 2005.

[92] J. Veliskova and S. L. Moshe, "Update on the role of substantia nigra pars reticulata in the regulation of seizures," Epilepsy Currents, vol. 6, no. 3, pp. 83-87, 2006.

[93] M. J. During, P. Leone, K. E. Davis, D. Kerr, and R. S. Sherwin, "Glucose modulates rat substantia nigra GABA release in vivo via ATP-sensitive potassium channels," The Journal of Clinical Investigation, vol. 95, no. 5, pp. 2403-2408, 1995.

[94] C. Zhou, C. Xiao, J. J. McArdle, and H. Y. Jiang, "Mefloquine enhances nigral $\gamma$-aminobutyric acid release via inhibition of cholinesterase," Journal of Pharmacology and Experimental Therapeutics, vol. 317, no. 3, pp. 1155-1160, 2006.

[95] S. Amoroso, H. Schmid-Antomarchi, M. Fosset, and M. Lazdunski, "Glucose, sulfonylureas, and neurotransmitter release: role of ATP-sensitive K+ channels," Science, vol. 247, no. 4944, pp. 852-854, 1990.

[96] J. M. Tepper and C. R. Lee, "GABAergic control of substantia nigra dopaminergic neurons," Progress in Brain Research, vol. 160, pp. 189-208, 2007.

[97] G. Di Chiara and A. Imperato, "Drugs abused by humans preferentially increase synaptic dopamine concentrations in the mesolimbic system of freely moving rats," Proceedings of the National Academy of Sciences of the United States of America, vol. 85, no. 14, pp. 5274-5278, 1988.

[98] P. W. Kaplan, A. O. Rossetti, E. H. Kaplan, and H.-G. Wieser, "Proposition: limbic encephalitis may represent limbic status epilepticus. A review of clinical and EEG characteristics," Epilepsy and Behavior, vol. 24, no. 1, pp. 1-6, 2012.

[99] J. G. Csernansky, D. B. Leiderman, M. Mandabach, and J. A. Moses Jr., "Psychopathology and limbic epilepsy: relationship 
to seizure variables and neuropsychological function," Epilepsia, vol. 31, no. 3, pp. 275-280, 1990.

[100] W. L. Lee, E. C. Dooling, M. A. Mikati, and G. R. Delong, "Limbic encephalopathy presenting as prolonged complex partial status epilepticus-a new entity," Annals of Neurology, vol. 24, no. 2, p. 359, 1988.

[101] G. R. Jeffreys, P. Jiruska, M. de Curtis, and M. Avoli, "Limbic network synchronization and temporal lobe epilepsy," in Jasper's Basic Mechanisms of the Epilepsies, J. L. Noebels, M. Avoli, and M. A. Rogowski, Eds., National Centre for Biotechnology Information, Bethesda, Md, USA, 2012.

[102] A. Meurs, R. Clinckers, G. Ebinger, Y. Michotte, and I. Smolders, "Substantia nigra is an anticonvulsant site of action of topiramate in the focal pilocarpine model of limbic seizures," Epilepsia, vol. 47, no. 9, pp. 1519-1535, 2006.

[103] L. W. Swanson, “The projections of the ventral tegmental area and adjacent regions: a combined fluorescent retrograde tracer and immunofluorescence study in the rat," Brain Research Bulletin, vol. 9, no. 1-6, pp. 321-353, 1982.

[104] Z. Z. Cui, C. R. Gerfen, and W. S. Young, "Hypothalamic and other connections with dorsal CA2 area of the mouse hippocampus," Journal of Comparative Neurology, vol. 521, no. 8, pp. 1844-1866, 2013.

[105] R. Chowdhury, C. Lambert, R. J. Dolan, and E. Düzel, "Parcellation of the human substantia nigra based on anatomical connectivity to the striatum," NeuroImage, vol. 81, pp. 191-198, 2013.

[106] A. Gasbarri, C. Verney, R. Innocenzi, E. Campana, and C. Pacitti, "Mesolimbic dopaminergic neurons innervating the hippocampal formation in the rat: a combined retrograde tracing and immunohistochemical study," Brain Research, vol. 668, no. 1-2, pp. 71-79, 1994.

[107] R. Speich and A. Haller, "Central anticholinergic syndrome with the antimalarial drug mefloquine," The New England Journal of Medicine, vol. 331, no. 1, pp. 57-58, 1994.

[108] N. Campbell, M. Boustani, T. Limbil et al., "The cognitive impact of anticholinergics: a clinical review," Clinical Interventions in Aging, vol. 4, pp. 225-233, 2009.

[109] J. E. Desmarais, L. Beauclair, and H. C. Margolese, "Anticholinergics in the era of atypical antipsychotics: short-term or longterm treatment?" Journal of Psychopharmacology, vol. 26, no. 9, pp. 1167-1174, 2012.

[110] T. J. Moore, J. Glenmullen, and C. D. Furberg, "Prescription drugs associated with reports of violence towards others," PLOS ONE, vol. 5, no. 12, Article ID e15337, 2010.

[111] K. Singh, G. D. Shanks, and H. Wilde, "Seizures after mefloquine," Annals of Internal Medicine, vol. 114, no. 11, p. 994, 1991.

[112] J. P. Bolam, J. J. Hanley, P. A. C. Booth, and M. D. Bevan, "Synaptic organisation of the basal ganglia," Journal of Anatomy, vol. 196, part 4, pp. 527-542, 2000.

[113] N. Matsumoto, S. Komiyama, and N. Akaike, "Pre- and postsynaptic ATP-sensitive potassium channels during metabolic inhibition of rat hippocampal CA1 neurons," Journal of Physiology, vol. 541, no. 2, pp. 511-520, 2002.

[114] H. Folkerts and H. Kuhs, "Psychotic episode following mefloquine malaria prophylaxis-case report," Nervenarzt, vol. 63, no. 5, pp. 300-302, 1992.

[115] P. C. Stuiver, R. J. Ligthelm, and T. J. L. M. Goud, "Acute psychosis after mefloquine," The Lancet, vol. 334, no. 8657, p. 282, 1989.
[116] D. J. Javorsky, G. Tremont, G. I. Keitner, and A. H. Parmentier, "Cognitive and neuropsychiatric side effects of mefloquine," Journal of Neuropsychiatry and Clinical Neurosciences, vol. 13, no. 2, p. 302, 2001.

[117] F. O. Nabih, M. Touhami, A. Laffinti, and L. Abilkacem, "Mood disorder after malaria prophylaxis with mefloquine (two case reports)," Encephale, vol. 37, no. 5, pp. 393-396, 2011.

[118] J. Velĩsková, L. Velĩsek, M. L. Nunes, and S. L. Moshé, “Developmental regulation of regional functionality of substantia nigra $\mathrm{GABA}_{\mathrm{A}}$ receptors involved in seizures," European Journal of Pharmacology, vol. 309, no. 2, pp. 167-173, 1996.

[119] J. Velikova and S. L. Moshe, "Sexual dimorphism and developmental regulation of substantia nigra function," Annals of Neurology, vol. 50, no. 5, pp. 596-601, 2001.

[120] F. O. ter Kuile, F. Nosten, M. Thieren et al., "High-dose mefloquine in the treatment of multidrug-resistant falciparum malaria," The Journal of Infectious Diseases, vol. 166, no. 6, pp. 1393-1400, 1992.

[121] R. M. van Dam, B. Hoebee, J. C. Seidell, M. M. Schaap, T. W. A. De Bruin, and E. J. M. Feskens, "Common variants in the ATPsensitive $\mathrm{K}^{+}$channel genes KCNJ11 (Kir6.2) and ABCC8 (SUR1) in relation to glucose intolerance: Population-based studies and meta-analyses," Diabetic Medicine, vol. 22, no. 5, pp. 590-598, 2005.

[122] S. Le Fur, D. Fradin, P. Boileau, and P. Bougnères, "Association of Kir6.2 and INS VNTR variants with glucose homeostasis in young obese," Physiological Genomics, vol. 22, no. 3, pp. 398-401, 2005.

[123] Y.-D. Jiang, L.-M. Chuang, D. Pei et al., "Genetic variations in the Kir6.2 subunit (KCNJ11) of pancreatic ATP-sensitive potassium channel gene are associated with insulin response to glucose loading and early onset of type 2 diabetes in childhood and adolescence in Taiwan," International Journal of Endocrinology, vol. 2014, Article ID 983016, 7 pages, 2014.

[124] P. Proks, J. F. Antcliff, J. Lippiat, A. L. Gloyn, A. T. Hattersley, and F. M. Ashcroft, "Molecular basis of Kir6.2 mutations associated with neonatal diabetes or neonatal diabetes plus neurological features," Proceedings of the National Academy of Sciences of the United States of America, vol. 101, no. 50, pp. 17539-17544, 2004.

[125] R. Männikkö, C. Jefferies, S. E. Flanagan, A. Hattersley, S. Ellard, and F. M. Ashcroft, "Interaction between mutations in the slide helix of Kir6.2 associated with neonatal diabetes and neurological symptoms," Human Molecular Genetics, vol. 19, no. 6, Article ID ddp554, pp. 963-972, 2010.

[126] S. J. Cruikshank, M. Hopperstad, M. Younger, B. W. Connors, D. C. Spray, and M. Srinivas, "Potent block of Cx36 and Cx50 gap junction channels by mefloquine," Proceedings of the National Academy of Sciences of the United States of America, vol. 101, no. 33, pp. 12364-12369, 2004.

[127] S. B. Bodendiek and G. Raman, "Connexin modulators and their potential targets under the magnifying glass," Current Medicinal Chemistry, vol. 17, no. 34, pp. 4191-4230, 2010.

[128] C. Ernst, C. Nagy, S. Kim et al., "Dysfunction of astrocyte connexins 30 and 43 in dorsal lateral prefrontal cortex of suicide completers," Biological Psychiatry, vol. 70, no. 4, pp. 312-319, 2011.

[129] I. Todt, H. C. Hennies, D. Basta, and A. Ernst, "Vestibular dysfunction of patients with mutations of connexin 26," Neuroreport, vol. 16, no. 11, pp. 1179-1181, 2005.

[130] R. Garbelli, C. Frassoni, D. F. Condorelli et al., "Expression of connexin 43 in the human epileptic and drug-resistant cerebral cortex," Neurology, vol. 76, no. 10, pp. 895-902, 2011. 
[131] K. Jiang, J. Wang, C. Zhao et al., "Regulation of gap junctional communication by astrocytic mitochondrial $\mathrm{K}_{\mathrm{ATP}}$ channels following neurotoxin administration in in vitro and in vivo models," NeuroSignals, vol. 19, no. 2, pp. 63-74, 2011.

[132] D. M. Cummings, I. Yamazaki, C. Cepeda, D. L. Paul, and M. S. Levine, "Neuronal coupling via connexin36 contributes to spontaneous synaptic currents of striatal medium-sized spiny neurons," Journal of Neuroscience Research, vol. 86, no. 10, pp. 2147-2158, 2008.

[133] R. L. Nevin, "Mefloquine blockade of connexin 36 and connexin 43 gap junctions and risk of suicide," Biological Psychiatry, vol. 71, no. 1, pp. el-e2, 2012.

[134] M. Vandecasteele, J. Glowinski, and L. Venance, "Connexin mRNA expression in single dopaminergic neurons of substantia nigra pars compacta," Neuroscience Research, vol. 56, no. 4, pp. 419-426, 2006.

[135] D. W. Allison, R. S. Wilcox, K. L. Ellefsen et al., "Mefloquine effects on ventral tegmental area dopamine and GABA neuron inhibition: a physiologic role for connexin-36 GAP junctions," Synapse, vol. 65, no. 8, pp. 804-813, 2011.

[136] M. Srinivas, M. G. Hopperstad, and D. C. Spray, "Quinine blocks specific gap junction channel subtypes," Proceedings of the National Academy of Sciences of the United States of America, vol. 98, no. 19, pp. 10942-10947, 2001.

[137] D. G. Margineanu and H. Klitgaard, "The connexin 36 blockers quinine, quinidine and mefloquine inhibit cortical spreading depression in a rat neocortical slice model in vitro," Brain Research Bulletin, vol. 71, no. 1-3, pp. 23-28, 2006.

[138] T. A. van Essen, R. S. van der Giessen, S. K. E. Koekkoek et al., "Anti-malaria drug mefloquine induces motor learning deficits in humans," Frontiers in Neuroscience, vol. 4, article 191, 2010.

[139] N. A. Levit, C. Sellitto, H. Wang et al., "Aberrant connexin26 hemichannels underlying keratitis-ichthyosis-deafness syndrome are potently inhibited by mefloquine," Journal of Investigative Dermatology, vol. 135, no. 4, pp. 1033-1042, 2015.

[140] B. Liss and J. Roeper, "ATP-sensitive potassium channels in dopaminergic neurons: transducers of mitochondrial dysfunction," News in Physiological Sciences, vol. 16, no. 5, pp. 214-217, 2001. 

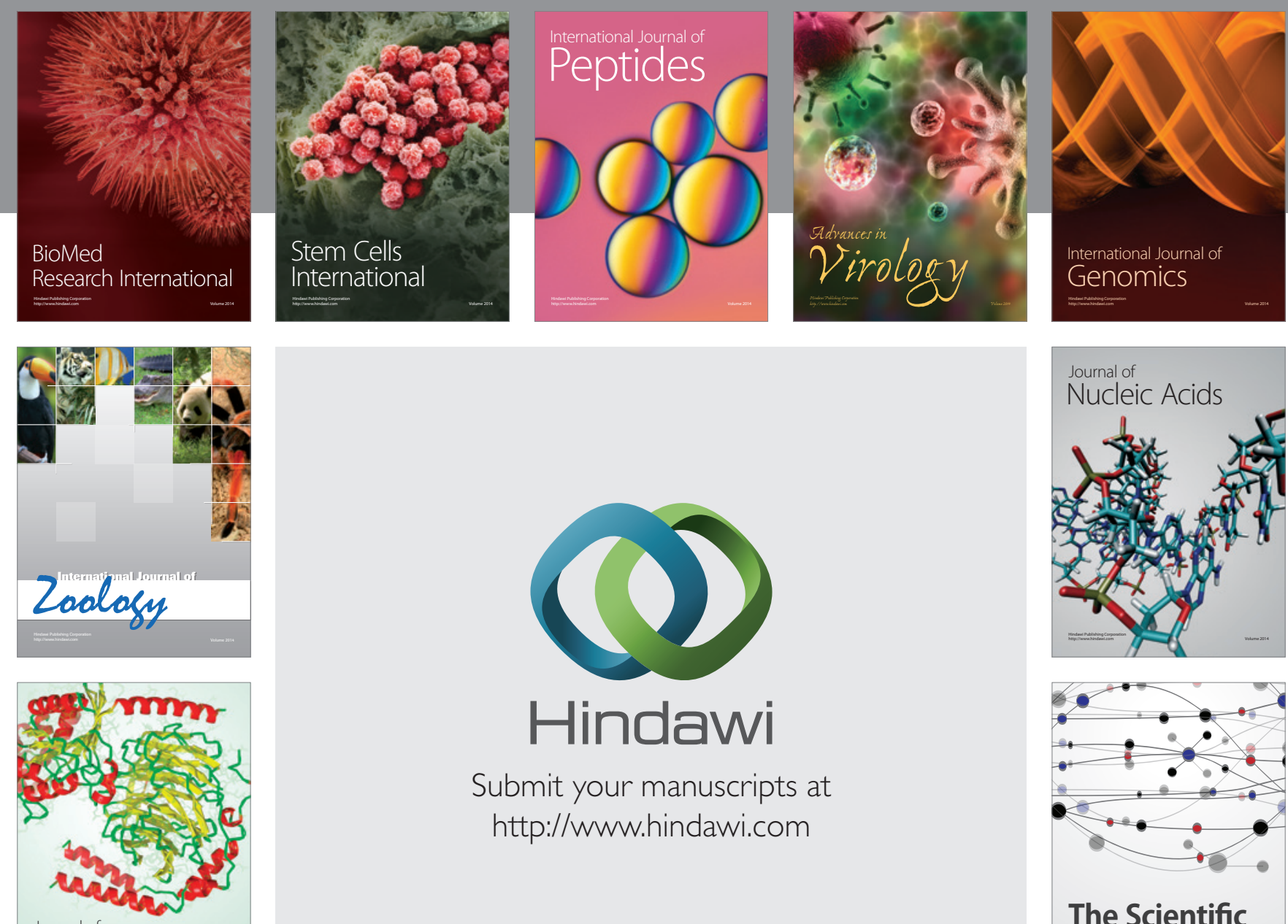

Submit your manuscripts at

http://www.hindawi.com

Journal of
Signal Transduction
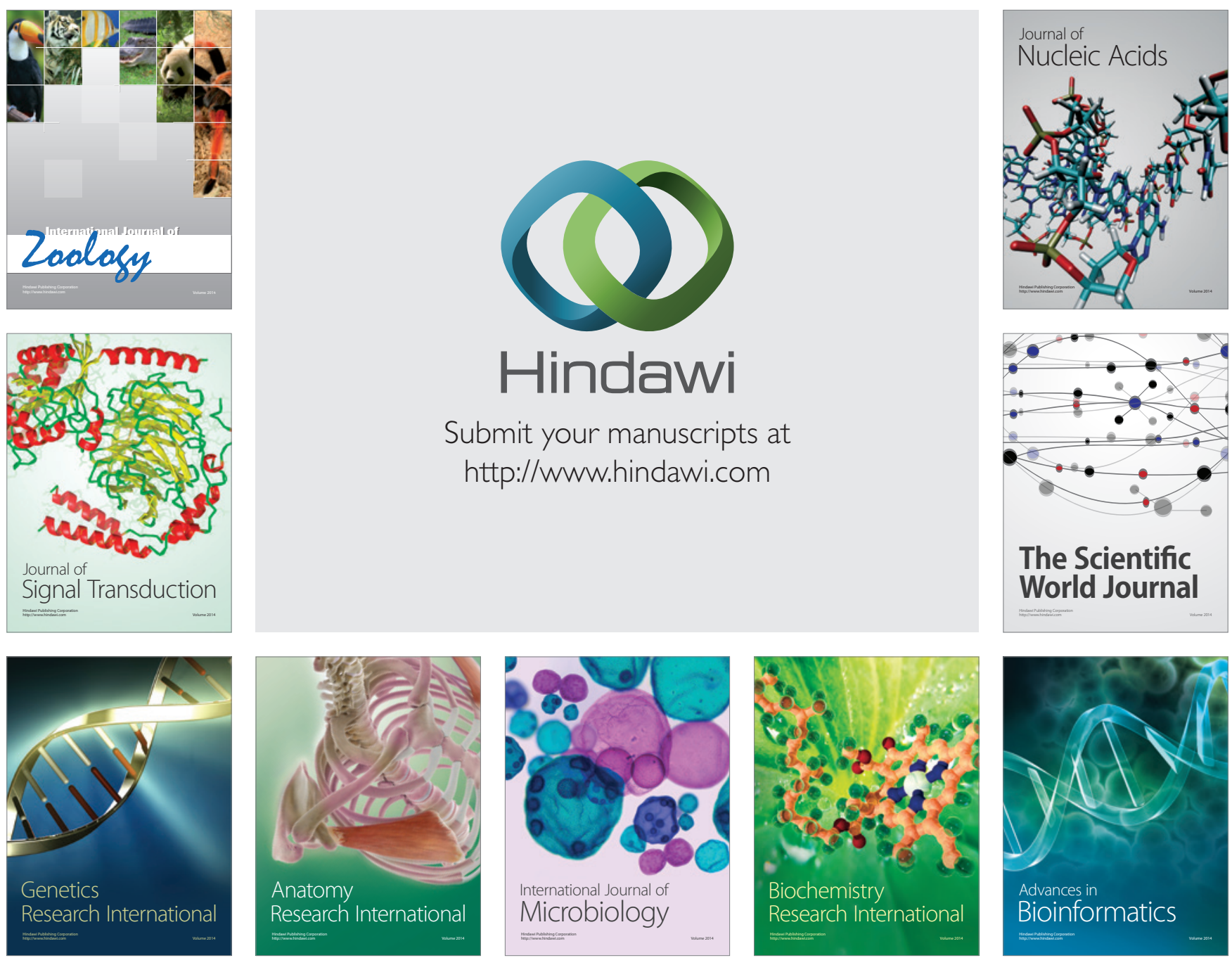

The Scientific World Journal
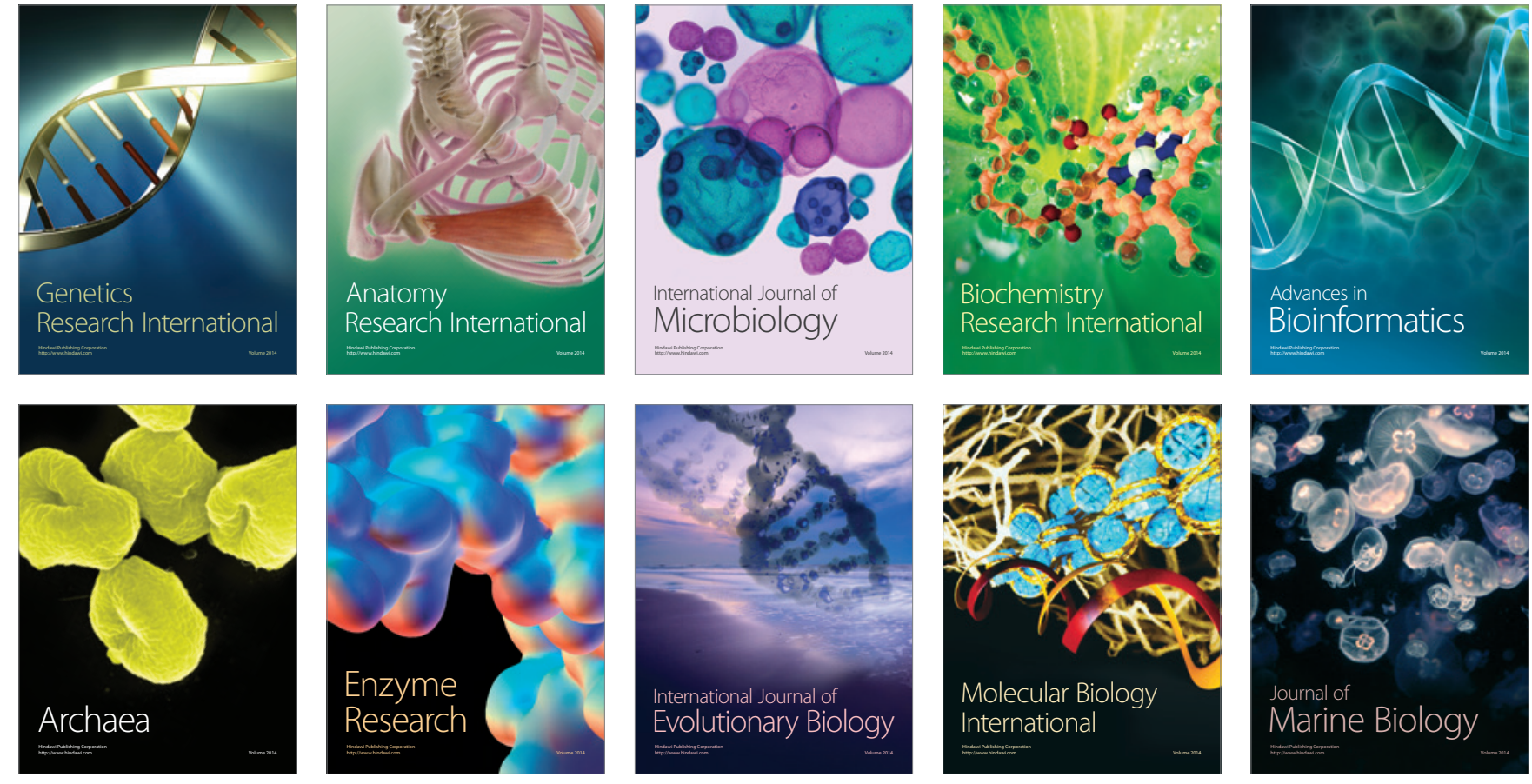